Bolm Inst. oceanogr., S Paulo, 32(2):117-124, 1983

\title{
DINÂMICA DE SEDIMENTAÇÃO DAS FEIÇÕES DE ASSOREAMENTO DAREGIÃO LAGUNAR CANANÉIA-IGUAPE, ESTADO DE SÃO PAULO
}

\author{
Moysés Gonsalez TESSLER \& Valdenir Veronese FURTADO
}

Instituto Oceanogräfico da Universidade de São Paulo

\begin{abstract}
Synopsis
The Cananéia-Iguape lagoonal complex is characterized by a continuous siltation, which is shown by sedimentary istands and sand spits frequently found within the lagoonal area. Two sets of aerial photos, one of 1962 and another of 1973 , and a nautical chart of the Brazilian Navy have been used to evaluate the morphological changes of those sedimentary features through the time. A close relationship between their orientation and local hydrodynamic processes has been obsemed in the "mar de Cubatão", "nar de Cananeia" and "mar Pequeno" areas.

bescriptors: Sedinentation, Cananéla-iguape, Valo Grande, State of Sào Paulo, Quaternary perice, futinals, S.diment transport, Sedimentary features, Sediment-water interface, Sediment depasiticin.

Descritores: Sedimentação, Cananéia-lquape, Valo Grande, Estado de São Paulo, Periodo quaternario, Canats.

Transporte de sedimento. Feiçōes sedinentares, Interface sedimento-água, Assoreamento
\end{abstract}

\section{Introdução}

o complexo lagunar de Cananéia-Iguape localiza-se no litoral sul do Estado de São Paulo, limitado pelas latitudes de $24^{\circ} 40^{\prime} \mathrm{S}$ e $25^{\circ} 05^{\prime} \mathrm{S}$ e pelas longitudes de $47^{\circ} 25^{\prime} \mathrm{W}$ e $48^{\circ} 00^{\prime} \mathrm{W}$. Possui duas saídas para o mar a SW e NE das regiões denominadas, respectivamente, barra de Cananéia e barra de Icapara. A região lagunar é separada do oceano adjacente por uma ilha barreira (ilha Comprida) com, aproximadamente, $70 \mathrm{~km}$ de extensão. A partir da porção intermediāria da ilha-barreira, estendendo-se para SW, situa-se a ilha de Cananéia, separada do continente e da ilha Comprida por dois canais lagunares, respectivamente, mar de Cubatão e mar de Cananéia. Esses canais interligam-se atravēs da Baía de Trapandē, na porção sul da região, e confluem, a partir da porção média, em um único canal (mar Pequeno) até a barra de Icapara.

Como característica típica de regiões semi-confinadas, esses canais apresentam tendência a assoreamento, evidenciado pela presença de feiçôes sedimentares de deposição (Besnard, 1950). Estas feiçôes foram avaliadas atravēs de fotografias aēreas e carta batimétrica, além de observaçōes de campo. A anālise mostrou, em alguns pontos, a formação de esporões ("spits") ou acrescimentos sedimentares com um sentido predominante de desenvolvimento que permite, além de verificar a tendência ao assoreamento dos canais,

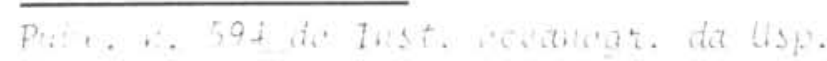

obter informaçôes sobre o sentido preferencial de transporte local (Allen, 1965).

\section{Gênese dos canais lagunares}

A gênese dos canais lagunares encontrase, segundo Suguio \& Martin (1978), associada ao mecanismo de evolução da região no Quaternārio e, portanto, vinculada às flutuações do nível do mar neste período. Esses autores propōem um modelo evolutivo caracterizado por cinco estădios marcades por duas transgressões marinhas, a transgressão Cananéia $( \pm 120$ mil anos A.C.) e a transgressão Santos (ültimos 5 mil anos), e êpocas de regressão marinha. Durante a primeira fase regressiva (pós-transgressäo Cananéia), foram escavados vales que, posteriormente, foram invadidos pelo mar durante a transgressão Santos, originando lagunas. Portanto, os canais lagunares atuais correspondem a feiçōes herdadas da ültima transgressão marinha.

\section{Morfologia dos canais lagunares}

A Figura 1 tem como base a carta náutica 1702 da Diretoria de Hidrografia e Navegação (DHN), que representa cartograficamente o mar de Cananéia (Fig. la-b) e o mar Pequeno (Fig. $1 \mathrm{c}-\mathrm{e}$ ).

o mar de Cananëia apresenta-se meandrante, possuindo um canal de circulação mais profundo, com profundidades maiores que $5 \mathrm{~m}$. Fora deste canal, encontram-se regiōes mais rasas com ilhas sedimenta- 


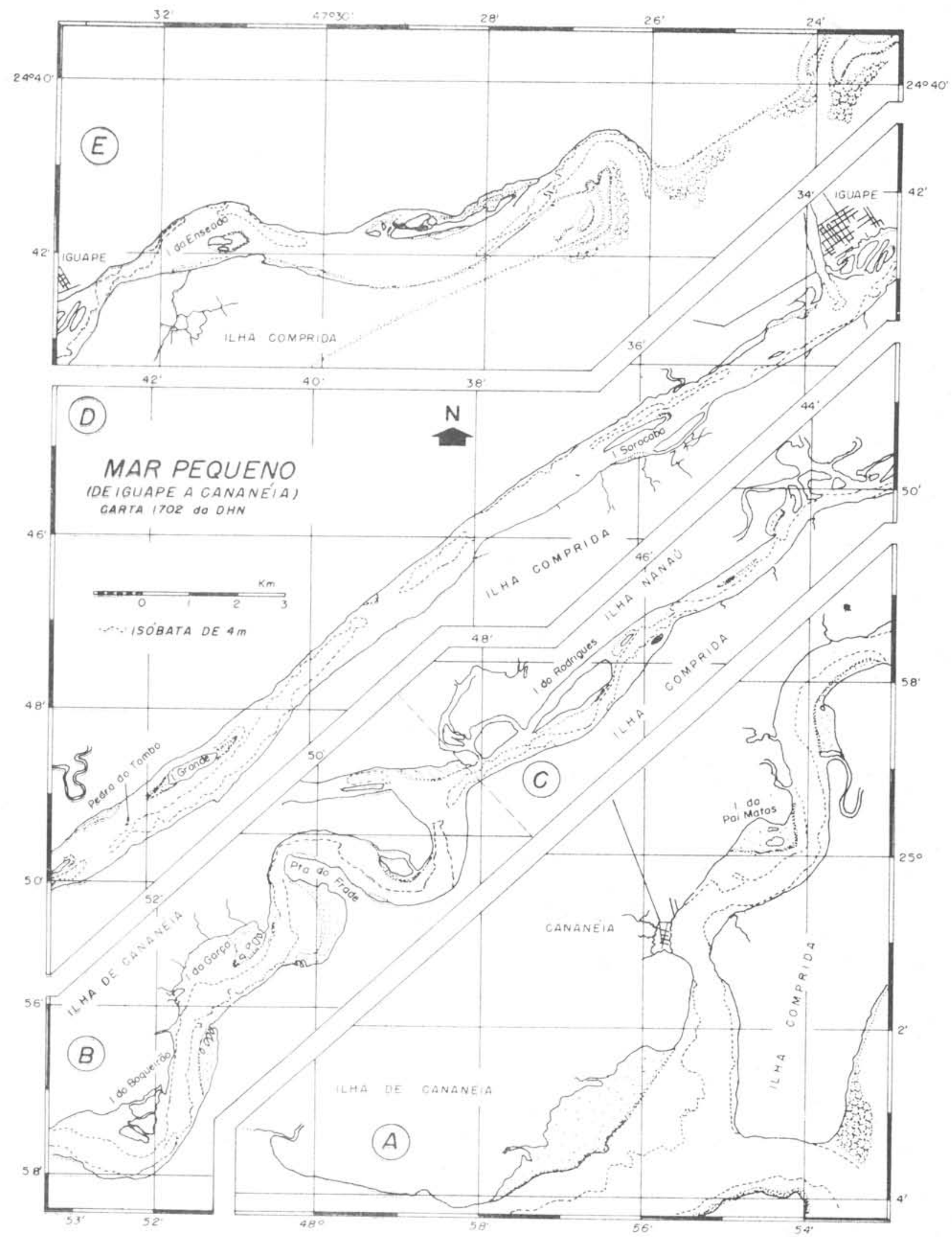

Fig. 1. Carta náutica n. 1702 da Diretoria de Hidrografia e Navegação do Ministério da Marinha (1969), com base na Carta original de 1938. 
res recobertas por manguezais (ilhas Pai Matos, Boqueirão, Garça, Furadinho etc). A região mais profunda do mar de Cananéia $(13 \mathrm{~m})$ coincide com a sua porção mais estreita, junto à ponta do Frade, que è uma feição de crescimento da ilha Comprida.

0 mar Pequeno é, em geral, pouco meandrante e, devido às suas características, foi divido por Tessler (1982) em dois. A primeira parte, que se estende da confluência NE dos mares de Cananëia e de Cubatão atē a pedra do Tombo (Fig. $1 c-d)$, denominada mar Pequeno. Esta região apresenta um canal mais profundo de circulação, ligeiramente meandrante, com diversas ilhas sedimentares. A segunda, que se estende da pedra do Tombo até a Barra de Icapara, foi denominada mar de Iguape. Nesta região, o canal mais profundo de circulação tem configuração mais retilínea e as ilhas sedimentares escasseiam.

O mar de Cubatão e a baía de Trapandē não possuem base batimétrica e cartogräfica em cartas nảuticas da DHN, Tessler (op. cit.) mapeou e descreveu essas äreas. o mar de Cubatão é a porção mais estreita do complexo lagunar. Possui profundidades acima de $5 \mathrm{~m}$ nas confluências com o mar Pequeno e mar de Cananéia e na confluência com a baía de Trapandé, pröximo ao rio Itapitangui. Apresenta-se ligeiramente meandrante sem a característica associaçăo com ilhas sedimentares, com exceção de alguns poucos 1ocais.

A baía de Trapandé pode ter até $3 \mathrm{~km}$ de largura e apresenta um canal mais profundo de circulação com profundidades maiores que $5 \mathrm{~m}$, 1 igando a barra de $\mathrm{Ca}-$ nanéia ao mar de Cubatão.

Tessler (op. cit.) traçou perfis batimétricos transversais à baîa de Trapandé (Fig. 2) e aos canais lagunares (Figs 3-4).

Os perfis transversais aos eixos dos canais lagunares mostram variações na sua geometria, exibindo, no entanto, sempre um canal mais profundo de circulaça. Neste, um dos flaneos é pouco inclinado e mais raso, sugerindo áreas de deposição mais intensa. O outro flanco, mais inclinado emais profundo, sugere deposiçäo mais lenta, Tal configuração não ê nîtida para toda a extensão do mar de Iguape, sendo mais prominente para o mar de Cananéia e mar Paqueno.
Para o mar de Cubatão, foi inviävel traçar perfis, em virtude da escassez de dados batimëtricos.

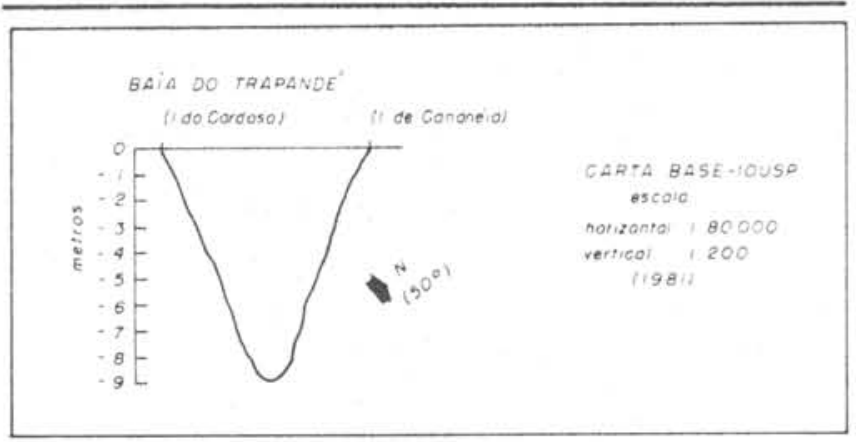

Fig. 2. Seção-tipo: perfil batimëtrico da baía de Trapandé.

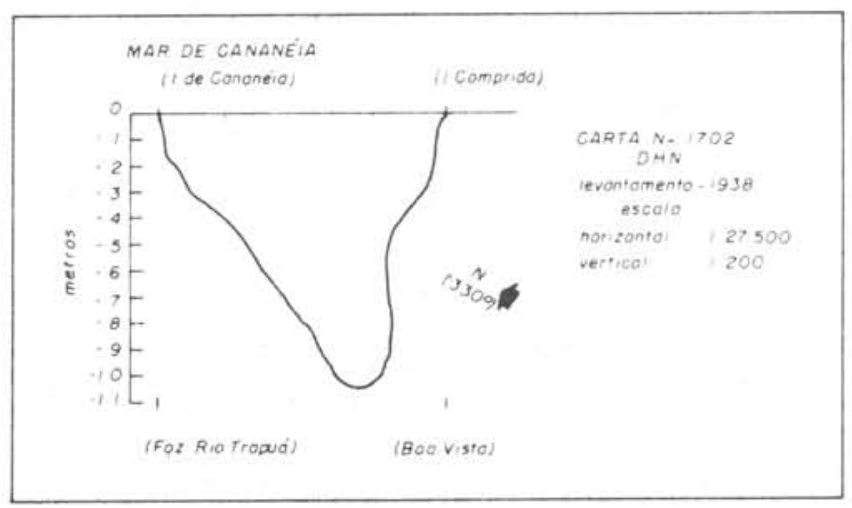

Fig. 3. Seção-tipo: perfil batimëtrico do mar de Cananéia.

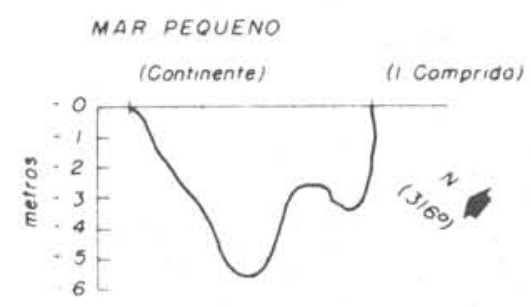

$$
\begin{aligned}
& \text { CARTAN. } 1702 \\
& \text { DHN } \\
& \text { levantamento-1938 } \\
& \text { escala } \\
& \text { horizontal }, 27500 \\
& \text { vertical }, 200
\end{aligned}
$$
MAR DE IGUAPE

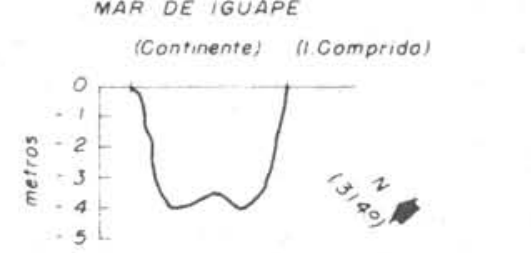

Fig. 4. Seção-tipo: perfis batimétricos dos mares Pequeno e de Iguape. 


\section{Comportamento e análise de ilhas sedimentares e esporões nos canais lagunares}

Feições sedimentares de deposição como pequenas ilhas, esporões e bancos submersos são freqüentes no mar Pequeno e mar de Cananéia e são perfeitamente evidenciadas na carta náutica n. 1702 (DHN, 1969). O mar de Cubatão caracteriza-se pela quase ausência de tais feições.

Para a anālise das feições sedimentares, foram utilizadas, alêm da carta näutica n. 1702 (DHN, 1969), dois conjuntos de fotografias aéreas. 0 primeiro, obtido pela empresa de aerofotogrametria Cruzeiro do Sul S.A. em 1962, pertence ao acervo do Departamento de Geografia da Faculdade de Filosofia, Letras e Ciências Humanas (USP). 0 segundo, foi obtido pela VASP Aerofotogrametria em 1973 e pertence ao acervo do Instituto Oceanogräfico (USP). Descrevem-se, no trabalho, algumas äreas, em especial, como a ponta do Frađe e ilha do Boqueirão (Fig. 1b), no mar de Cananéia, a îlha do Aceiro Grande, no mar de Cubatão (Fig. 7), e o conjunto de ilhas presentes no mar Pequeno (Fig. 1c) e mar de Iguape (Fig. 1d-e).

As feiçoes presentes no mar de Cananéia, pela comparação das fotos aéreas, mostram uma tendência ao crescimento $1 \hat{i}$ gado a um fluxo unidirecional, apresentando um sentido preferencial de crescimento. Tais feições são semelhantes às formas descritas por King (1959) e Zenkovitch (1967). As feições descritas por esses autores, no entanto, originamse a partir de correntes geradas por refração de ondas ("1ongshore currents") ao passo que as formas presentes no mar de Cananéia originam-se a partir de correntes de maré.

As Figuras 5-6 mostram esquematicamente a evolução das feições sedimentares presentes no mar de Cananéia.

A ponta do Frade é um esporão que cresce a partir da ilha Comprida, dis-

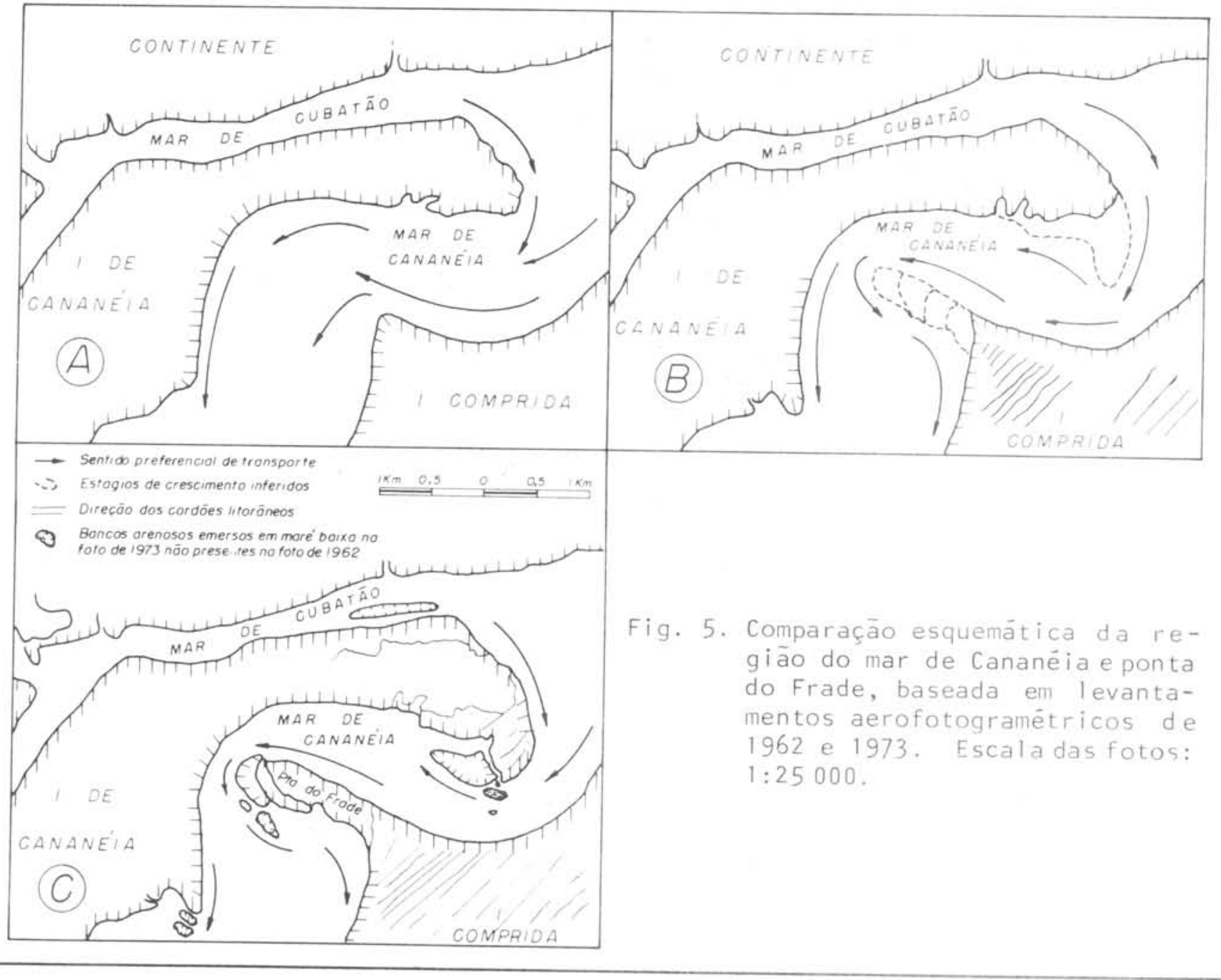


pondo-se transversalmente ao canal lagunar. A anālise das fotografias aéreas permite detectar diferentes fases de sua evolução e avaliar o acrescimento progressivo a essa feição de novos bancos isolados, de configuração geométrica semelhante aos jā incorporados e emersos na ponta do Frade.

A proximidade e disposição dos novos bancos arenosos são indicativos de um processo de crescimento do esporão no sentido da ilha de Cananéia. Os acrescimentos causam um alargamento sucessivo da ponta do Frade e um estreitamento 1ocal no canal lagunar, com aumento de profundidade. 0 mecanismo de acrescimento de material tem sua origem em fluxo unidirecional no sentido da barra de
Cananéia. A Figura 5 ilustra os estādios de evolução da feição, atravēs de acümulo de sedimentos em função dessas correntes. A Figura 5 a corresponde a um estädio preliminar, com o esporão ainda incipiente. Na Figura $5 b$ tem-se um estảdio intermediārio, onde se nota o mecanismo responsāvel pelo crescimento da feição. A Figura $5 c$ corresponde à configuração atual da feição. Nota-se, ainda, na Figura 5, a ilustração do crescimento de feições adjacentes à ponta do Frade. Não havendo dados que confirmem uma evolução sinōtica ou indiquem as velocidades de crescimento das feições, o esquema deve ser visto apenas como ilustrativo do mecanismo de crescimento, não se tendo idéia da velocidade com que

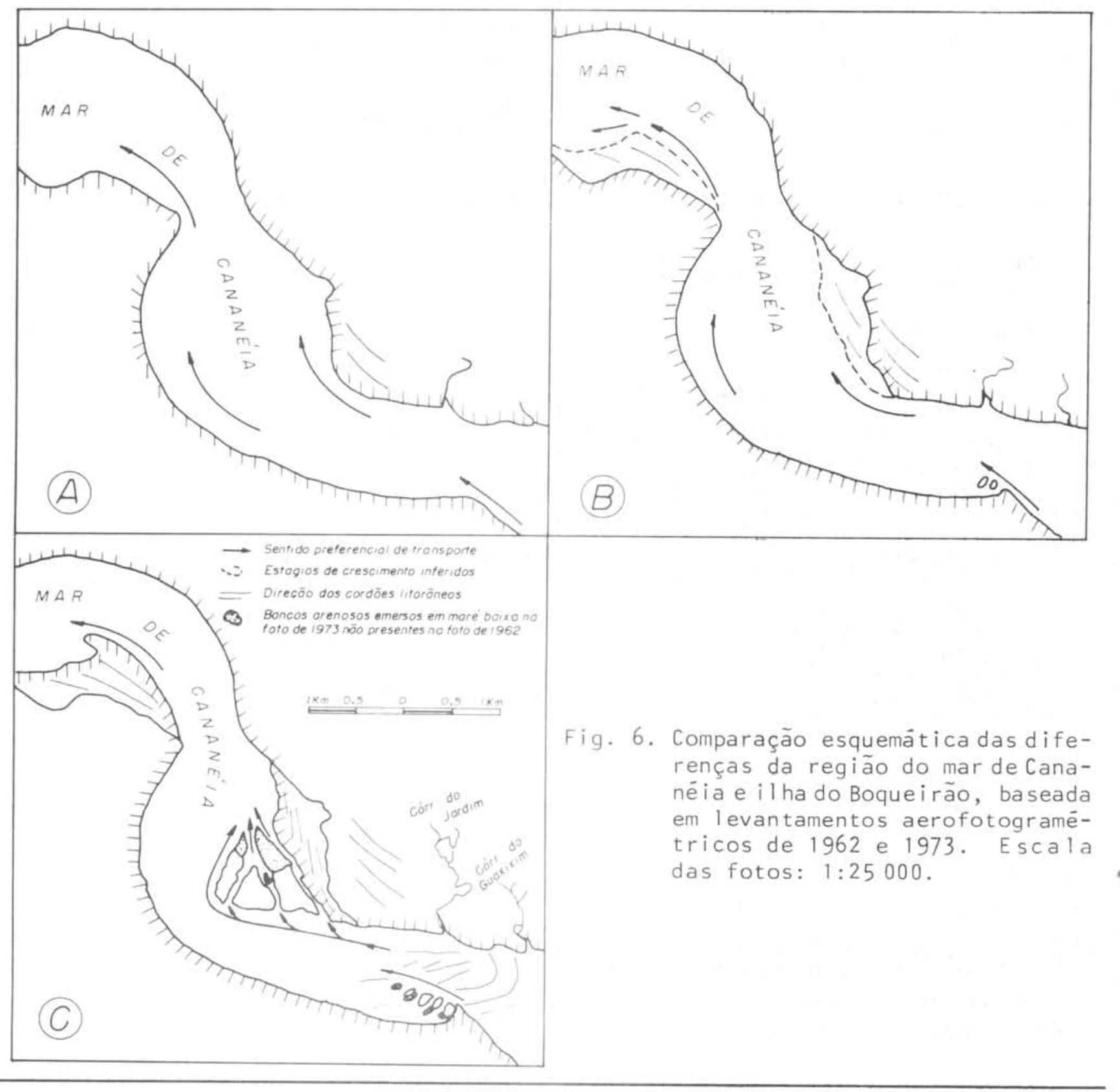




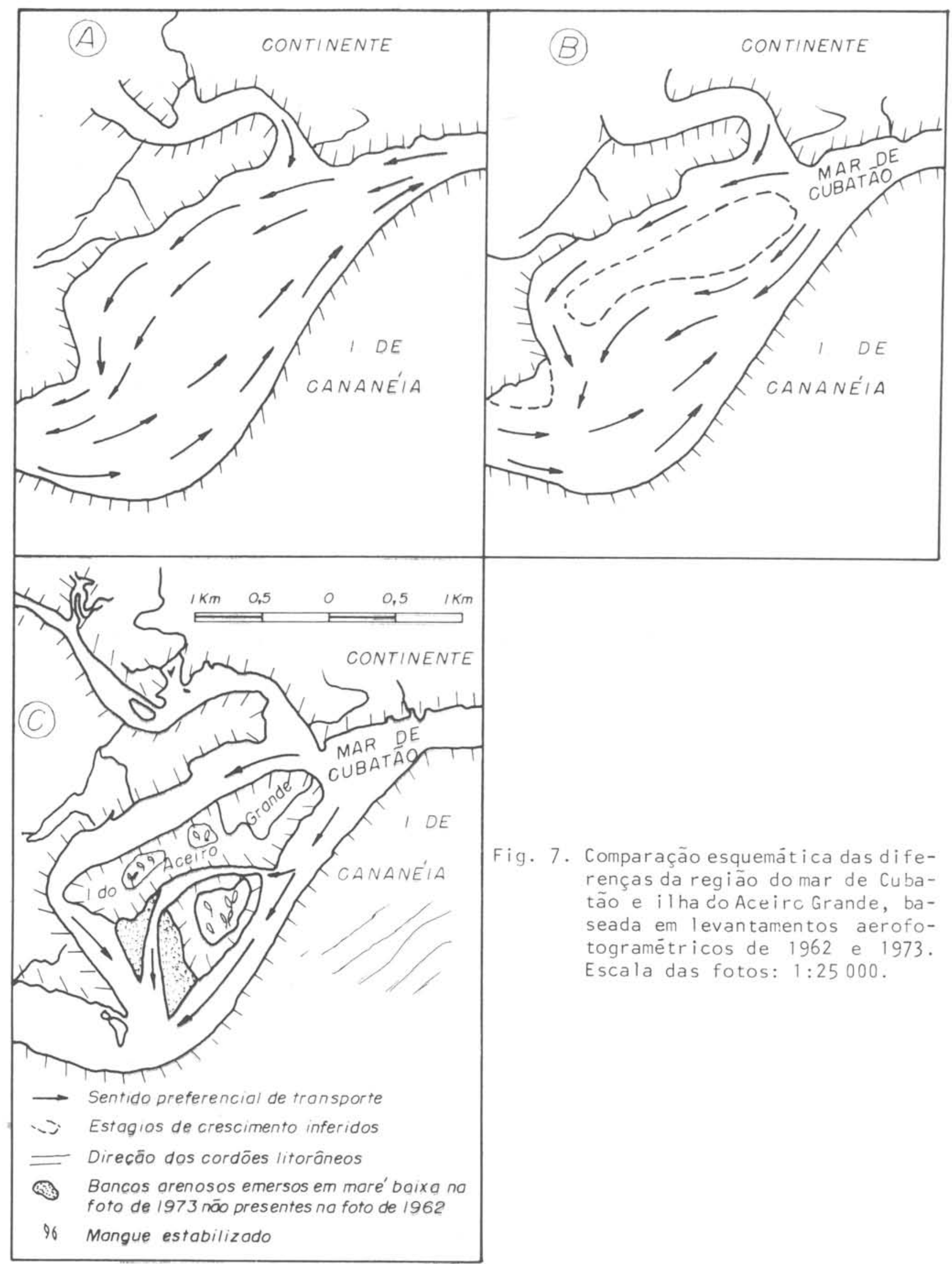


ocorre o fenômeno.

A ilha do Boqueirão é constituída por uma sucessão de pequenas ilhas sedimentares e bancos arenosos separados por estreitos canais, não estando, portanto, totalmente unidos à ilha de Cananéia. A ilha do Boqueirão apresenta um crescimento pronunciado em direção a ilha Comprida e uma tendência ao alongamento das pequenas ilhas que a formam em direção à barra de Cananéia. o crescimento se dá, à semelhança da ponta do Frade, pelo acréscimo de material, o que, nas fotografias aéreas, pode ser evidenciado por um alinhamento de cordões arenosos. 0 processo é indicativo de um alargamento da ilha de Cananéia.

A Figura 6 esquematiza os estádios de evolução da ilha do Boqueirão. A Figura $6 a$ corresponde ao acrescimento inicial da ilha de Cananéia, com a presença de cordões litorâneos e as feições que dão a configuração atual à ilha do Boqueirão, ainda não implantadas. Na Figura $6 b$, tem-se a incorporação de um banco arenoso à ilha de Cananéia, iniciando-se, assim, a formação da ilha do Boqueirão. A Figura $6 c$ corresponde à configuração atual da feição sedimentar.

A gênese e a forma dessas feições no mar de Cananéia leva a concluir haver o predomínio de transporte de sedimentos, junto ao fundo, no sentido das correntes de maré vazante. 0 alongamento das feições em direção à barra de Cananêia fornece um bom indício deste fato, visto serem as correntes aí presentes devidas à ação de marés (Miyao, 1976).

0 mar de Cubatão destaca-se pela quase ausência dessas feições sedimentares emersas, constituindo uma exceção a ilha do Aceiro Grande. A gênese dessa ilha e de bancos arenosos associados ocorre por um mecanismo de acrescimento semelhante ao que deu origem às feições anteriores porém, no caso, tem-se a contribuição efetiva de material fornecido pelo rio Iririaia-Açu. 0 transporte fluvial, conjugado à ação das correntes de maré, dā origem à ilha do Aceiro Grande. 0 material fornecido pelo rio é represado e retrabalhado pela dinâmica do canal, sendo redistribuído, preferencialmente, no sentido das correntes de vazante, constatando-se um alongamento nítido neste sentido. Associam-se ao material fluvial, sedimentos retrabalhados de outras partes do canal lagunar e suas margens. A Figura 7 ilustra, esquematica- mente, a evolução na foz do rio IririaiaAçu. A Figura $7 a$ mostra um estágio preliminar sem a ilha. Na Figura $7 b$, témse o estágio intermediärio jā com a presença da ilha e o crescimento de feições associadas. A Figura $7 c$ ilustra a configuração atual da ārea.

Utilizando-se a divisão de Tessler (1982), observa-se, para o mar Pequeno, a manutenção do alongamento em direção à barra de Cananéia, ou seja, coincidente com a vazante, visto a pedra do Tombo corresponder à ārea de encontro de marés. Este fato pode ser observado na ilha de Rodrigues (Fig. 1C), com nítido alongamento em direção à barra de Cananéia.

No mar de Iguape, da pedra do Tombo até a região do Valo Grande, não há acrescimentos característicos de fluxo unidirecional e sim formas mais compatíveis com a ação de alternância de fluxo, ou seja, fluxos bidirecionais, como é o caso das ilhas Grande e Sorocaba (Fig. 1d). Há, portanto, um equilíbrio na ação de distribuição do material, entre as correntes de enchente e vazante. $\mathrm{Tal}$ equilíbrio durante as inversões de fluxo torna esta região muito calma, com predominância de pelitos. Tal fato foi evidenciado pelo mapeamento dos sedimentos de fundo efetuado por Tessler (1982). A partir da região do Valo Grande rumo à barra de Icapara, novamente as feições sedimentares alongam-se em um sentido coincidente com a maré vazante, sendo características de fluxos unidirecionais. Como exemplo, tém-se a ilha da Enseada (Fig. 1d).

\section{Conclusões}

As formas assumidas pelas ilhas sedimentares nos canais lagunares e a sua evolução sugerem, nitidamente, que o transporte e a deposição dos sedimentos obedecem a uma direção preferencial coincidente com as correntes de maré geradas na vazante. Tal fato é especialmente evidente no mar de Cananéia.

No mar de Iguape, até a região do Va1o Grande, as feições mostram um acrescimento bidirecional nítido atestando uma redistribuição homogênea do material, relacionada às correntes geradas tanto na enchente como na vazante da maré. A partir do Valo Grande até a barra de Icapara, a ação das correntes geradas na vazante da maré é nítida.

A comparação das fotografias aêreas de 1962 e 1973 não permite estimar as 
taxas de crescimento anual dessas feições, pois não há informações sobre a fase de maré em que foram obtidas as fotos de 1962. Porém, levando-se em conta que, segundo Mesquita (1983), o nível médio da maré na regiäo tem se elevado à razão de $1,5 \mathrm{~cm} /$ ano, pode-se admitir um crescimento significativo destas feições no período analisado. E välido, portanto, supor-se que os canais lagunares estejam submetidos a um efetivo e pronunciado processo de as soreamento.

Essas feições sedimentares, bem como os cordões litorâneos, podem estar 1igados a flutuações do nível do mar, além do processo hidrodinâmico atual. Porém, o curto período de análise dessas feições sedimentares não permite avaliar as suas relações com as mudanças de niveis marinhos em processo, preconizadas por Suguio \& Martin (1978).

\section{Resumo}

o complexo lagunar de Cananéia e Iguape apresenta tendências ao assoreamento em seus canais lagunares (Kutner, 1962). Estas tendências podem ser visualizadas através de modificações nos canais ocasionadas pelo crescimento de feições sedimentares, como pequenas ilhas e esporões.

Para a avaliação das modificaçöes sofridas por essas feições, com o tempo, foram usados dois conjuntos de fotografias aéreas, um obtido em 1962 e outro em 1973, além da carta náutica n. 1708 da DHN e observações de campo.

0 trabalho procura evidenciar o crescimento dessas feições no mar de Cananéia, mar de Cubatão e mar Pequeno, esquematizando provāveis estágios de evolução e associando o sentido de crescimento das feições à dinâmica local.

\section{Agradecimentos}

Agradecemos à FINEP, pelo suporte financeiro do Subprojeto "Sedimentação em regiões costeiras e plataforma continental de São Paulo", do qual este trabalho faz parte.

\section{Referências bibliográficas}

ALLEN, J. R. L. 1965. Sedimentation to the lee of small underwater sand waves: an experimental study. J. Geo1., 73(1):95-116.
BESNARD, W. 1950. Considerações gerais em torno da região lagunar Cananéia Iguape. Bolm Inst. paul. Oceanogr., $1(1): 3-28$.

CRUZEIRO DO SUL S/A. 1962. Levantamento aerofotogramétrico da região sul do Estado de São Paulo, Cananéia Iguape. Fotos aéreas na escala $1: 25.000$.

DIRETORIA DE HIDROGRAFIA E NAVEGAÇÃO (DHN). 1969. Carta n? 1702 Escala 1:27.000 - Rio de Janeiro.

KING, C. A. M. 1959. Beaches and coasts. London, Edward Arnold, 403 p.

KUTNER, A. S. 1962. Granulometria dos sedimentos de fundo da região de Cananéia, S.P. Bolm Soc. bras. Geol., $11(2): 41-54$.

MIYAO, S.Y. 1976. Estudo de alguns aspectos da região estuarina de Cananéia. Dissertação de mestrado. Universidade de São Paulo, Instituto Oceanográfico, $87 p$.

MESQUITA, A. R. de 1983. Os"terrenos de marinha" e a Antārtica. Jorn. IOUSP, Bolm inf., 1(3):8-13.

SUGUIO, K.\& MARTIN, L. 1978. Formações quaternárias marinhas do litoral paulista e Sul fluminense. International Symposium on Coastal Evolution in the Quaternary-Special Publicationn. 1The Brazilian National Working Group for the IGCP, Project 61. Universidade de São Paulo, Instituto de Geociências, 550p.

TESSLER, M.G. 1982. Sedimentação atual na região lagunar de Cananéia-Iguape, Estado de São Paulo. Dissertação de mestrado. Universidade de São Pau1o, Institutode Geociências, 2 v.

VASP AEROFOTOGRAMETRIA S/A. 1973. Levantamento aerofotogramétrico - fotografias aéreas na escala $1: 25.000$.

ZENKOVITCH. V. D. 1967. Process of coastal development. Edinburgh, Oliver and Boyd, $738 \mathrm{p}$.

(Recebido 22-iu1-1983; aceito 20-set-1983) 